\title{
Gender but not diabetes, hypertension or smoking affects infarct evolution in ST- elevation myocardial infarction patients - data from the CHILL-MI, MITOCARE and SOCCER trials
}

David Nordlund ${ }^{1} \mathbb{D}$, Henrik Engblom 1 , Jean-Louis Bonnet ${ }^{2}$, Henrik Steen Hansen ${ }^{3}$, Dan Atar ${ }^{4}$, David Erlinge ${ }^{5}$, Ulf Ekelund ${ }^{6}$, Einar Heiberg ${ }^{1,7}$, Marcus Carlsson ${ }^{1}$ and Håkan Arheden ${ }^{1 *}$

\begin{abstract}
Background: Infarct evolution rate and response to acute reperfusion therapy may differ between patients, which is important to consider for accurate management and treatment of patients with ST-elevation myocardial infarction (STEMI).

The aim of this study was therefore to investigate the association of infarct size and myocardial salvage with gender, smoking status, presence of diabetes or history of hypertension in a cohort of STEMI-patients.
\end{abstract}

Methods: Patients $(n=301)$ with first-time STEMI from the three recent multi-center trials (CHILL-MI, MITOCARE and SOCCER) underwent cardiac magnetic resonance (CMR) imaging to determine myocardium at risk (MaR) and infarct size (IS). Myocardial salvage index (MSI) was calculated as MSI=1-IS/MaR. Pain to balloon time, culprit vessel, trial treatments, age, TIMI grade flow and collateral flow by Rentrop grading were included as explanatory variables in the statistical model.

Results: Women ( $n=66$ ) had significantly smaller MaR (mean difference: $5.0 \pm 1.5 \%$ of left ventricle $(L V), p<0.01)$, smaller IS (mean difference: $5.1 \pm 1.4 \%$ of $L V, p=0.03$ ), and larger MSI (mean difference: $9.6 \pm 2.8 \%$ of LV, $p<0.01$ ) compared to men $(n=238)$. These differences remained significant when adjusting for other explanatory variables. There were no significant effects on MaR, IS or MSI for diabetes, hypertension or smoking.

Conclusions: Female gender is associated with higher myocardial salvage and smaller infarct size suggesting a pathophysiological difference in infarct evolution between men and women.

Keywords: Area at risk, Gender, Sex, Diabetes, Hypertension

\section{Introduction}

Ischemic heart disease (IHD) is a major cause of death worldwide. In the acute setting of IHD, a coronary occlusion may cause ischemia which gradually develops into myocardial infarction unless the myocardium is reperfused [1-3]. Reperfusion therapy has revolutionized the care for these patients but the decision whether to

\footnotetext{
* Correspondence: hakan.arheden@med.lu.se

'Department of Clinical Physiology, Clinical Sciences, Lund University, Lund, Sweden

Full list of author information is available at the end of the article
}

reperfuse or not is sensitive to timing relative to the ischemic injury [4]. To fully utilize the potential of reperfusion therapy it's important to understand which factors affect infarct evolution and thus may help determine when reperfusion is appropriate. In addition, the main determinant of long term prognosis in these patients have been shown to be infarct size [5-8], further stressing the need to understand the progression of the disease.

Factors such as gender, smoking, history of hypertension and diabetes have all been implicated to affect risk after 
acute myocardial infarction. It has been shown that women have higher mortality compared to men after acute myocardial infarction [9] although one study reported the difference only applies to younger women and might be attributed to comorbidities [10]. There are conflicting results regarding if smoking is associated with lower mortality [11] or not [12] after acute myocardial infarction, which has resulted in the concept of "smokers' paradox" stating that smoking could be beneficial in the acute setting of myocardial ischemia. History of hypertension increases the risk for adverse events after myocardial infarction [13] and hypertension is associated with a reduced myocardial blood supply $[14,15]$ as well as an increased oxygen demand which may affect the pathophysiology of myocardial infarction. Presence of diabetes at the time of ischemic injury is associated with higher mortality and development of heart failure [16, 17], even when adjusted for systolic function [18].

It is not clear what mechanisms could explain differences in prognosis and pathophysiology or how they relate to the development of acute ischemic injury during coronary occlusion. Quantifying the extent of injury is therefore an important step towards better understanding of the pathophysiology associated with acute ischemic myocardial injury. Cardiovascular magnetic resonance (CMR) enables quantification of both irreversibly damaged myocardium, infarct size $[19,20]$, and myocardium at risk, which constitutes the myocardium that would have been injured if no reperfusion occurred [21-23] (MaR). Infarct size and MaR can be used to calculate myocardial salvage index [24] (MSI). Thus, CMR can be used to study infarct evolution [25] and which factors affect it.

Our aim was therefore to investigate to what extent gender, smoking status, presence of diabetes or history of hypertension affects the rate at which infarct evolves by assessing the amount of infarction and myocardial salvage observed using CMR in a cohort of ST elevation myocardial infarction (STEMI) patients from three recent multi-center trials.

\section{Methods}

\section{Study population}

Patients from the CHILL-MI (NCT01379261), MITOCARE (EudraCT Number 2010-024616-33) and SOCCER (NCT01423929) trials underwent CMR imaging 18 days after primary percutaneous coronary intervention (PCI) for first-time STEMI using previously published inclusion and exclusion criteria [26-29]. All patients had clinical signs of acute myocardial infarction including clinical symptoms and ECG signs consistent with STEMI, were $\geq 18$ years old and had symptom duration $<6 \mathrm{~h}$. Patients with a history of myocardial infarction or coronary revascularization were excluded. The CHILLMI, MITOCARE and SOCCER trials were approved by the local or regional institutional review boards/ethics committees and all patients provided written consent.

\section{Trial interventions}

Hypothermia was induced prior to PCI for patients in the CHILL-MI trial randomized to treatment group as previously described [26]. The SOCCER trial randomized patients to either receive oxygen therapy or room air via an OxyMask ${ }^{\mathrm{m}}$ from inclusion in the ambulance to the end of the PCI [29]. In the MITOCARE trial, patients were randomized to receive a potentially cardioprotective compound (TRO40303) or placebo [28] at the time of acute reperfusion therapy. None of the three trial treatments showed any statistically significant effect on MaR, IS or myocardial salvage.

\section{Coronary angiography}

Culprit vessel was determined by coronary angiography and the ischemic injury was designated as anterior (left anterior descending artery) or non-anterior (right coronary artery or left circumflex artery). Coronary artery flow before PCI was graded according to the thrombolysis in myocardial infarction (TIMI) grading system and coronary collateral flow was graded according to the Rentrop grading system [30].

\section{CMR}

The CMR examinations were undertaken on scanners of $1.5 \mathrm{~T}$ field strenght from Philips (Philips Healthcare, Best, the Netherlands), Siemens (Siemens AG, Erlangen, Germany) or General Electrics (GE Healthcare, Waukesha, WI, USA). All subjects were imaged in a supine position. ECG gating was used and images were acquired at end-expiratory breath hold. Black blood triple inversion recovery T2-weighted (T2-STIR) images were acquired including full coverage of the left ventricle from base to apex prior to administration of an intravenous gadoliniumbased extracellular contrast agent $(0.2 \mathrm{mmol} / \mathrm{kg})$. Contrast-enhanced steady state free precession (CE-SSFP) images were acquired approximately $5 \mathrm{~min}$ after contrast injection including short-axis images corresponding to the T2-STIR images. Slice thickness was $8 \mathrm{~mm}$ with no slice gap. In-plane resolution was typically $1.5 \times 1.5 \mathrm{~mm}$.

\section{CMR analysis}

The software Segment, version 1.9R3314 (http://segment.heiberg.se), was used to analyze images [31]. MaR was quantified from the CE-SSFP images according to a previously published method [23] except for two cases where CE-SSFP images were not of diagnostic quality. In those cases, T2-STIR images were used to determine $\mathrm{MaR}$ since it has earlier been demonstrated that in diagnostic cases, CE-SSFP and T2-STIR images perform equally well [32]. In short, epicardial and endocardial borders of the left ventricle (LV) were delineated in T2STIR images and in both end-diastole and end-systole for 
CE-SSFP images. Subsequently, MaR was identified as hyperintense myocardium and delineated in T2-STIR images and in both end-diastole and end-systole for CE-SSFP images where the mean of those two values was used. Infarct was delineated in short-axis late gadolinium enhancement (LGE) images according to a previously described automatic method where endo- and epicardium is delineated manually and a computer algorithm is applied taking partial volume effects into account [33]. Manual adjustments were performed if necessary. If present, hypointense myocardium within the hyperintense area in the CE-SSFP/T2STIR and LGE images was included as MaR or infarct respectively (microvascular obstruction or hemorrhagic infarct). The delineations were performed by in consensus between two or out of three experienced observers (HE, $\mathrm{MC}$ and HA with 13, 14 and 20 years of experience) where the third observer was brought in when opinions differed between the first two. Observers had access to LGE images when delineating T2-STIR and CE-SSFP. MaR and infarct sizewere expressed as \% of the LV mass while MSI was expressed as \% of MaR.

\section{Statistical analysis}

Statistical analyses were performed using SPSS (IBM, SPSS Statistics, Version 23). Continuous parameters are expressed as mean \pm standard deviation and categorical parameters are expressed as per cent of total. Independent samples t-tests were used to compare population characteristics between men and women for continuous variables and Fisher's exact test was used for categorical variables. To explain infarct development, myocardium at risk, infarct and myocardial salvage multivariable linear regressions were used. MaR and infarct were described as \% of left ventricular mass while MSI was described as \% of MaR. Univariable linear regression analysis was used to determine which parameters to include in the multivariable analysis. The parameters included in the univariable analysis were: age (continuous variable), pain to balloon time (continuous variable), female gender (yes/no), troponin $\mathrm{T}$ levels of $<15 \mathrm{ng} / \mathrm{L}$ (yes/no), left ventricular mass (LVM, continuous variable), LVM per body surface area (LVM/BSA, continuous variable), current smoker (yes/no), current smoker or ex-smoker (yes/no), diabetes (yes/no), hypertension (yes/no), treated with hypothermia (yes/no), treated with oxygen (yes/no), treated with TRO40303 (yes/no), anterior injury (yes/no), TIMI 0 flow before reperfusion (yes/ no), Rentrop grade 0 of the culprit vessel (yes/no). BSA was calculated by the Du Bois Formula [34]. Multivariable linear regression analyses were performed using all parameters with $p<0.10$ from the univariable analyses. As LVM and LVM/BSA have a high covariance they were included in separate multivariable analyses where the ones including LVM/BSA can be found in the
Appendix. The variance inflation factor was found to be $<2.0$ for all variables included in the multivariable analysis. A $p$-value of $<0.05$ was considered to indicate statistical significance.

\section{Results \\ Study population}

Diagnostic CMR data of MaR was available from 298 subjects, of infarct from 285 subjects and of MSI from 282 subjects. Population characteristics are summarized in Table 1. An overview of the results is shown in Fig. 1. Example CMR images used to measure infarct and MaR are shown in Fig. 2.

\section{Myocardium at risk}

Gender, anterior injury, LVM, and hypothermia were found to be variables associated with $\mathrm{MaR}$ in the univariable analysis (Table 2). Female gender was associated with smaller MaR while anterior injury and adjuvant hypothermia-treatment was associated with larger MaR in the multivariable analysis (Table 3 ).

\section{Infarct}

Gender, current smoker, smoker or ex-smoker, anterior injury, age, LVM, LVM/BSA, and TIMI grade flow were variables found to be associated with infarct size in the univariable analysis Table 2). Female gender was associated with smaller infarct size while anterior injury and TIMI flow grade 0 before PCI was associated with larger infarct size in the multivariable analysis (Table 4).

\section{Myocardial salvage}

Gender, smoker or ex-smoker, anterior injury, age, LVM, LVM/BSA, and TIMI grade flow were variables found to be associated with MSI in the univariable analysis (Table 2). Female gender was associated with larger MSI while anterior injury, age, and TIMI flow grade 0 before PCI was associated with smaller MSI in the multivariable analysis (Table 5).

\section{Discussion}

This study shows that in the highly controlled setting of three multi-center trials in STEMI patients, women had smaller myocardium at risk, smaller infarct size, and larger myocardial salvage index. Myocardium at risk, infarct, and MSI were unaffected by smoking, presence of diabetes, and history of hypertension.

\section{Gender difference}

In previous studies women had poorer prognosis than men following STEMI $[35,36]$ and it has been debated whether this is due to differences in age and comorbidities or whether there is a biological difference, for example resulting in larger injuries in women. The worse prognosis seems, however, to be primarily short-term 
Table 1 Population characteristics

\begin{tabular}{|c|c|c|c|c|c|c|c|}
\hline & Total $(n=301)$ & Missing (n) & Women $(n=66)$ & Missing (n) & Men $(n=235)$ & Missing (n) & $p$-value \\
\hline Age, years & $61 \pm 12$ & 0 & $67 \pm 10$ & 0 & $60 \pm 12$ & 0 & $<0.001$ \\
\hline Pain to balloon, min & $184 \pm 73$ & 103 & $194 \pm 78$ & 35 & $182 \pm 72$ & 68 & 0.376 \\
\hline Pre $\mathrm{PCl}$ TnT $<15$ ng/L, \% & 48 & 5 & 38 & 3 & 51 & 2 & 0.089 \\
\hline \multicolumn{8}{|l|}{ Risk factors } \\
\hline Current smoker, \% & 39 & 9 & 37 & 1 & 39 & 8 & 0.774 \\
\hline Smoker or ex-smoker, \% & 59 & 9 & 62 & 0 & 55 & 0 & 0.399 \\
\hline Diabetes, \% & 12 & 0 & 20 & 0 & 9 & 0 & 0.029 \\
\hline Hypertension, \% & 30 & 1 & 42 & 1 & 26 & 0 & 0.022 \\
\hline \multicolumn{8}{|l|}{ Treatments } \\
\hline Hypothermia, \% & 16 & 0 & 14 & 0 & 17 & 0 & 0.576 \\
\hline Oxygen, \% & 48 & $206^{a}$ & 53 & 34 & 46 & 172 & 0.524 \\
\hline TRO40303, \% & 18 & 0 & 11 & 0 & 20 & 0 & 0.101 \\
\hline \multicolumn{8}{|l|}{ Angiography } \\
\hline Anterior injury, \% & 42 & 1 & 37 & 1 & 43 & 0 & 0.395 \\
\hline TIMI 0, \% & 76 & 1 & 73 & 0 & 76 & 1 & 0.520 \\
\hline Rentrop 0, \% & 66 & 9 & 73 & 4 & 68 & 15 & 0.536 \\
\hline \multicolumn{8}{|l|}{ CMR } \\
\hline LVM, g & $126 \pm 28$ & 0 & $106 \pm 30$ & 0 & $132 \pm 24$ & 0 & $<0.001$ \\
\hline LVM/BSA, $\mathrm{g} / \mathrm{m}^{2}$ & $65 \pm 14$ & 0 & $60 \pm 18$ & 0 & $66 \pm 12$ & 0 & 0.001 \\
\hline MaR, \% of LVM & $34 \pm 11$ & 3 & $30 \pm 11$ & 0 & $35 \pm 11$ & 3 & 0.001 \\
\hline Infarct, \% of LVM & $17 \pm 10$ & 16 & $13 \pm 10$ & 2 & $18 \pm 10$ & 14 & $<0.001$ \\
\hline MSI, \% of MaR & $53 \pm 20$ & 19 & $61 \pm 20$ & 2 & $51 \pm 20$ & 17 & 0.001 \\
\hline
\end{tabular}

Population characteristics are shown as mean \pm SD or valid per cent. CMR values of MaR and infarct are expressed as \% of LVM while MSI is expressed as \% of MaR

${ }^{\mathrm{a}}$ Reliable data on whether a patient received oxygen in the acute phase of ischemia was only available for patients included in the SOCCER trial ( $\left.n=95\right)$. Pre PCI $\mathrm{TnT}<15 \mathrm{ng} / \mathrm{L}=$ a blood sample acquired before coronary intervention showing a troponin $\mathrm{T}$ value $<15 \mathrm{ng} / \mathrm{L}, \mathrm{TRO} 40303=$ the study treatment in the mitocare trial LVM left ventricular mass, BSA body surface area, MaR myocardium at risk, MSI myocardial salvage index

[36, 37] and may even be better for women long-term [37] which could be consistent with smaller infarct size since that has been shown to affect long-term prognosis [5-7].The data from this study does not support a larger injury in women but rather points towards that age- and comorbidity matched women have higher myocardial salvage and thus develop smaller injury. This is in line with a previous study by Canali et al. [38], also showing a greater MSI in women compared to men, but not with Eitel et al. [39] or Langhans et al. [40] who found no difference in infarct size, MaR or MSI between men and women. Langhans et al., however, included patients with both STEMI and non-STEMI which could potentially make a difference in the natural course of myocardial infarction and thus the size of the injury. Additionally, MaR measurements have been validated for STEMI but not NSTEMI and since the magnitude of the ischemiareperfusion injury is likely different it is not clear if the MR measurements of MaR are accurate for NSTEMI. The study by Eitel et al. includes similar patients as in the present study but has women with significantly longer pain to balloon time than men and significantly more women with anterior injury which could explain part of what sets the results apart from this study, even if statistical adjustments were made. The aforementioned studies by Canali et al., Eitel et al., and Langhans et al. used CMR to measure infarct size and MaR. Mehilli [41] et al. performed a study on acute myocardial infarction patients where they measured size of injury and MaR using myocardial perfusion SPECT and found, similarly to this study, that women had smaller infarct size and greater myocardial salvage. In contrast to our study, Mehilli et al. included both STEMI and NSTEMI patients with wider inclusion criteria, patients receiving either thrombolysis or percutaneous coronary intervention (PCI) and patients with prior myocardial infarction while this study includes only first time STEMI-patients undergoing primary $\mathrm{PCI}$.

In summary, previous results have been mixed with some studies showing that women have higher MSI and smaller infarcts, both in selected STEMI-populations and in less selected populations, while others show no 


\section{Gender}

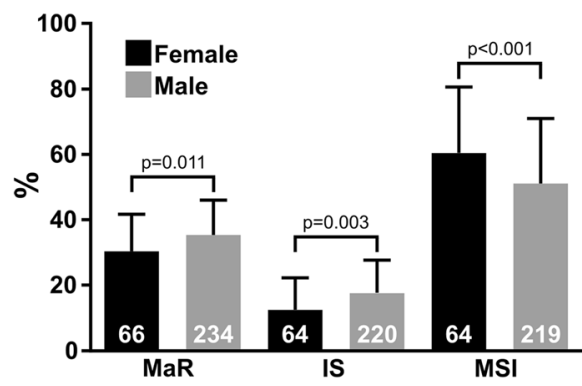

Presence of Diabetes

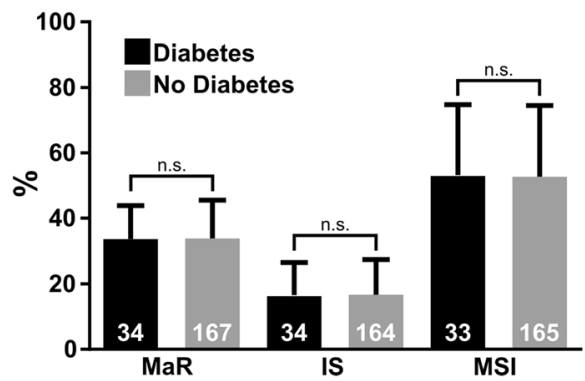

Smoking status

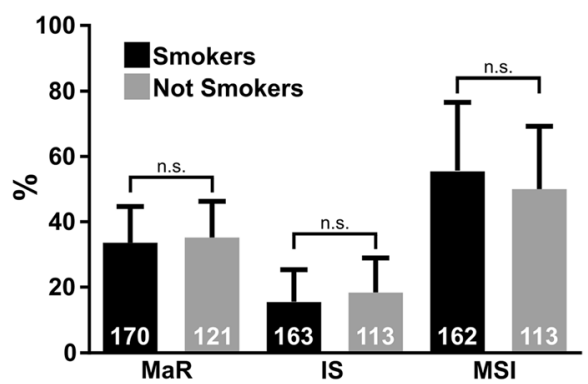

History of Hypertension

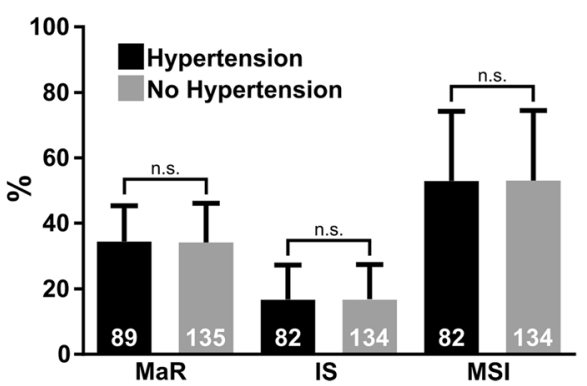

Fig. 1 Comparisons of MaR, IS and MSI for gender, smoking status, presence of diabetes and history of hypertension. The number of datapoints included in each analysis is shown in white on the staples. The $p$-values shown are adjusted for confounders by multivariable analysis as can be seen in Tables 3, 4 and 5. MaR, IS and MSI are shown as \% of left ventricular mass. MaR= Myocardium at risk, IS=Infarct size, MSI = Myocardial salvage index

difference. Our study adds evidence supporting higher MSI and smaller infarcts in women in a well-defined population with similar characteristics for men and women compared to previous results.

This difference has implications when designing cardioprotection trials, both regarding the importance of

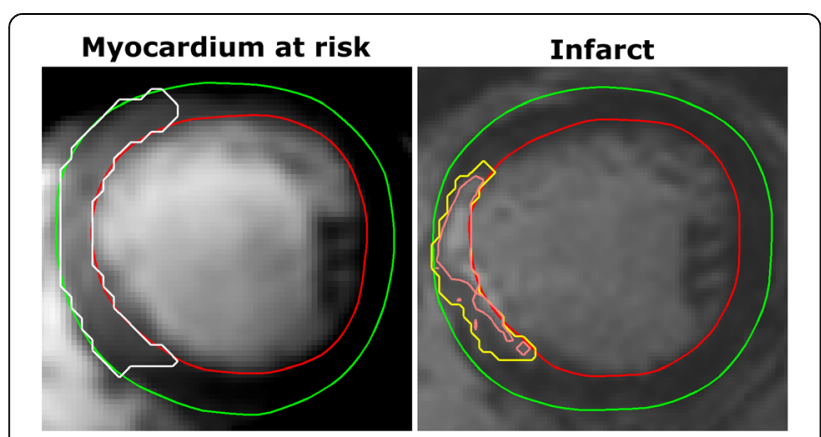

Fig. 2 Example CMR images illustrating the measurement of myocardium at risk and infarct. The left image shows one time-frame from a mid-ventricular stack of a CE-SSFP cine stack. The green line denotes epicardium, the red line endocardium and the white line the borders of myocardium at risk. The right image shows the

corresponding slice from a late gadolinium enhancement stack used to quantify infarct size using a previously published method [33]. In short, the yellow line shows the area of interest while the inner pink line takes intensities and partial volume effects into account. MaR in this patient was $23 \%$ of LVM, infarct size was $7 \%$ of LVM and the resulting myocardial salvage index was $70 \%$ of the MaR balancing men and women in the study arms and regarding how ratio of women in the trial might affect sample size [42].

As infarct size is one of the strongest predictors of long-term outcome and as high myocardial salvage show good treatment efficacy, it therefore seems that women would have the potential for better outcomes compared to men. Why this does not seem to be the case in bigger, less selected, materials needs to be further elucidated.

\section{Smokers' paradox}

The expression "smokers' paradox" comes from the notion that smokers may have lower mortality compared to non-smokers after a myocardial infarction [11, 43]. There are however conflicting results showing that this may be a result of differences in baseline characteristics between smokers and non-smokers [12]. Similarly, results in this study show that smokers have smaller infarct size and higher MSI in the univariable analysis but that the difference disappears when adjusting for baseline characteristics. These results should be related to a recent study by Symons et al. who showed less left ventricular remodeling after STEMI in smokers compared to non-smokers which remained when adjusting for, among other parameters, infarct size and MSI [44]. Thus, it appears that there are still possible explanations for a better prognosis after STEMI in smokers compared to non-smokers but the results of 
Table 2 Univariable analysis

\begin{tabular}{|c|c|c|c|c|c|c|c|c|c|}
\hline & \multicolumn{3}{|l|}{ MaR } & \multicolumn{3}{|c|}{ Infarct size } & \multicolumn{3}{|l|}{$\mathrm{MSI}$} \\
\hline & Coeff & SE & $p$-value & Coeff & SE & $p$-value & Coeff & SE & $p$-value \\
\hline Age & 0.0 & 0.1 & 0.866 & 0.1 & 0.1 & 0.213 & -0.2 & 0.1 & 0.059 \\
\hline Pain to balloon & 0.0 & 0.0 & 0.262 & 0.0 & 0.0 & 0.512 & -0.0 & 0.0 & 0.143 \\
\hline Female gender & -5.0 & 1.5 & 0.001 & -5.0 & 1.4 & $<0.001$ & 9.8 & 2.8 & 0.001 \\
\hline Pre $\mathrm{PCl} \mathrm{TnT}<15 \mathrm{ng} / \mathrm{L}$ & 1.0 & 1.3 & 0.419 & -1.8 & 1.2 & 0.148 & 5.8 & 2.4 & 0.015 \\
\hline LVM & 0.1 & 0.0 & 0.004 & 0.1 & 0.0 & $<0.001$ & -0.2 & 0.0 & $<0.001$ \\
\hline LVM/BSA & 0.1 & 0.0 & 0.053 & 0.1 & 0.0 & 0.001 & -0.3 & 0.1 & 0.001 \\
\hline \multicolumn{10}{|l|}{ Risk factors } \\
\hline Current smoker & -1.0 & 1.3 & 0.465 & -2.4 & 1.3 & 0.057 & 3.8 & 2.5 & 0.138 \\
\hline Smoker or ex-smoker & -1.5 & 1.3 & 0.237 & -2.8 & 1.2 & 0.021 & 5.3 & 2.4 & 0.030 \\
\hline Diabetes & -0.7 & 2.0 & 0.719 & -0.1 & 1.9 & 0.972 & 0.0 & 3.8 & 0.997 \\
\hline Hypertension & 0.1 & 1.4 & 0.966 & 0.1 & 1.3 & 0.936 & -0.2 & 2.7 & 0.929 \\
\hline \multicolumn{10}{|l|}{ Treatments } \\
\hline Hypothermia & 2.8 & 1.7 & 0.100 & -0.2 & 1.6 & 0.882 & 3.0 & 3.2 & 0.357 \\
\hline Oxygen & 2.2 & 2.3 & 0.346 & -0.2 & 2.2 & 0.940 & 3.7 & 5.0 & 0.467 \\
\hline TRO40303 & 1.4 & 1.7 & 0.408 & 1.0 & 1.6 & 0.544 & -1.7 & 3.2 & 0.603 \\
\hline \multicolumn{10}{|l|}{ Angiography } \\
\hline Anterior injury & 10.9 & 1.1 & $<0.001$ & 9.0 & 1.1 & $<0.001$ & -9.4 & 2.4 & $<0.001$ \\
\hline TIMI 0 & 3.5 & 1.5 & 0.019 & 5.7 & 1.3 & $<0.001$ & -12.4 & 2.7 & $<0.001$ \\
\hline Rentrop 0 & -3.4 & 1.4 & 0.018 & -2.0 & 1.4 & 0.139 & 0.4 & 2.7 & 0.894 \\
\hline
\end{tabular}

Pre $\mathrm{PCl} \mathrm{TnT}<15 \mathrm{ng} / \mathrm{L}=$ a blood sample acquired before coronary intervention showing a troponin $\mathrm{T}$ value $<15 \mathrm{ng} / \mathrm{L}$, TRO40303 = the study treatment in the mitocare trial

LVM left ventricular mass, BSA body surface area

this study imply that these explanations do not include lower MSI or infarct size.

\section{Diabetes and hypertension}

Diabetic patients have been shown to have worse outcomes after STEMI $[16,17,45,46]$. Based on the findings in the present study, this cannot be explained by differences in MSI or infarct size compared to nondiabetic patients. This points to other factors being important for a worse prognosis in diabetic patients, such as increased risk of recurring ischemic events [47], long term effects on cardiac/vessel innervation [48] or the addition of microvascular dysfunction to epicardial coronary disease. Compared to diabetes, the data on prognosis for patients with STEMI and a history of hypertension are more ambiguous as both worse and better prognosis has been shown [13, 49] and it has been suggested that the injury may develop due to different pathophysiological mechanisms [49]. The present study showed no difference in the development of infarct in patients with history vs no history of hypertension.

Table 3 Multivariable analysis, MaR

\begin{tabular}{lllll}
\hline Variable & Regression coefficient & SE & Partial correlation & $p$-value \\
\hline Model $r^{2}=33$ & & & & \\
Female gender & -3.5 & 1.4 & -0.1 & 0.015 \\
Anterior injury & 11.5 & 1.1 & 0.5 & 0.1 \\
Hypothermia & 4.1 & 1.5 & 0.1 & 0.005 \\
TIMI 0 & 3.2 & 1.3 & -0.1 & 0.014 \\
Rentrop 0 & -2.0 & 1.2 & -0.0 & 0.095 \\
LVM & -0.0 & 0.0 & 0.707 \\
\hline
\end{tabular}

LVM normalized to body surface area was also tested, showing no differences in significance levels, but as covariance with LVM is high it is presented in a separate analysis found in the Appendix LVM left ventricular mass 
Table 4 Multivariable analysis, Infarct size

\begin{tabular}{|c|c|c|c|c|}
\hline Variable & Regression coefficient & SE & Partial correlation & $p$-value \\
\hline \multicolumn{5}{|l|}{ Model $r^{2}=0.29$} \\
\hline Female gender & -3.2 & 1.4 & -0.1 & 0.018 \\
\hline Current smoker & 0.2 & 1.5 & 0.0 & 0.896 \\
\hline Smoker or ex-smoker & -1.9 & 1.4 & -0.1 & 0.192 \\
\hline Anterior injury & 8.4 & 1.1 & 0.4 & $<0.001$ \\
\hline TIMI 0 & 5.3 & 1.2 & 0.2 & $<0.001$ \\
\hline LVM & 0.0 & 0.0 & 0.1 & 0.217 \\
\hline
\end{tabular}

LVM normalized to body surface area was also tested, showing no differences in significance levels, but as covariance with LVM is high it is presented in a separate analysis found in the Appendix

LVM left ventricular mass

\section{Anterior injury and left ventricular mass}

As expected, anterior injuries had larger $M a R$ and infarct compared to non-anterior injuries. Note, however, that MSI was lower for anterior injuries suggesting that infarct develops faster for this group. Thus, larger MaR in the patients with anterior injuries might contribute to a faster infarct development. Van der Pals et al. [50] have shown presence of a lateral perfusion gradient within ischemic myocardium in dogs, where the edges of MaR are better perfused than the core during coronary occlusion. If this gradient exists in humans it could explain why injuries with larger $\mathrm{MaR}$ would have a relatively larger core area that is less perfused and therefore develops infarct faster.

At least one earlier study, on 100 patients, has reported a relation between the LVM and infarct size as measured by biomarkers which could not be seen in the current study [51]. It should be noted that the CMRbased measures in the current study are all normalized, either directly or indirectly, to LVM. A possible interpretation is therefore that while the area affected by ischemia is larger in absolute values in hearts with higher LVM, the rate at which infarct develops remains constant relative to this area.

\section{Limitations}

The present study uses data from three different trials and pools data from both treatment and control groups which is a potential limitation. All three trials were negative however and the data was controlled for differences between treatment groups and controls. Reliable data on whether oxygen was administered or not during the acute phase of ischemia was available only for patients included in the SOCCER trial. However, as the trial was designed to detect differences in myocardial salvage, MaR, and infarct size, and did not detect any such differences, it is unlikely that this would affect the results in the present study. Data on pain to balloon time was missing in one of the studies. Pain to balloon time did not show any trend towards significance in the remaining data and it is thus unlikely that this will affect results.

\section{Conclusions}

Female gender, but not diabetes, hypertension or smoking, was associated with smaller infarct size and higher myocardial salvage when adjusting for confounders, suggesting a pathophysiological difference in infarct evolution between men and women.

Table 5 Multivariable analysis, MSI

\begin{tabular}{|c|c|c|c|c|}
\hline Variable & Regression coefficient & SE & Partial correlation & $p$-value \\
\hline \multicolumn{5}{|l|}{ Model $r^{2}=0.20$} \\
\hline Age & -0.2 & 0.1 & -0.1 & 0.064 \\
\hline Female gender & 9.1 & 3.0 & 0.2 & 0.002 \\
\hline Smoker or ex-smoker & 2.5 & 2.3 & 0.1 & 0.270 \\
\hline Anterior injury & -6.5 & 2.3 & -0.2 & 0.005 \\
\hline TIMI 0 & -12.0 & 2.6 & -0.3 & $<0.001$ \\
\hline Pre PCI TnT $<15$ ng/L & 5.3 & 2.3 & 0.1 & 0.022 \\
\hline LVM & -0.1 & 0.0 & -0.1 & 0.133 \\
\hline
\end{tabular}

LVM normalized to body surface area was also tested, showing no differences in significance levels, but as covariance with LVM is high it is presented in a separate analysis found in the Appendix. Pre $\mathrm{PCl} \mathrm{TnT}<15 \mathrm{ng} / \mathrm{L}=$ a blood sample acquired before coronary intervention showing a troponin $\mathrm{T}$ value $<15 \mathrm{ng} / \mathrm{L}$ LVM left ventricular mass 


\section{Appendix}

Multivariable analyses using left ventricular mass (LVM) normalized to body surface area instead of plain LVM.

Table 6 Multivariable analysis, MaR

\begin{tabular}{lllll}
\hline Variable & $\begin{array}{l}\text { Regression } \\
\text { coefficient }\end{array}$ & SE & Partial correlation & p-value \\
\hline Model $r^{2}=33$ & & & & \\
Female gender & -3.4 & 1.3 & -0.1 & 0.011 \\
Anterior injury & 11.4 & 1.1 & 0.5 & $<0.001$ \\
Hypothermia & 4.0 & 1.5 & 0.1 & 0.006 \\
TIMI 0 & 3.2 & 1.3 & 0.1 & 0.013 \\
Rentrop 0 & -2.1 & 1.2 & -0.1 & 0.082 \\
LVM/BSA & -0.0 & 0.0 & -0.0 & 0.652 \\
\hline
\end{tabular}

LVM/BSA left ventricular mass/body surface area

Table 7 Multivariable analysis, Infarct size

\begin{tabular}{lllll}
\hline Variable & $\begin{array}{l}\text { Regression } \\
\text { coefficient }\end{array}$ & SE & $\begin{array}{l}\text { Partial } \\
\text { correlation }\end{array}$ & $p$-value \\
\hline Model $r^{2}=0.29$ & & & & \\
Female gender & -3.4 & 1.3 & -0.1 & 0.009 \\
Current smoker & 0.4 & 1.5 & 0.0 & 0.795 \\
Smoker or ex-smoker & -2.0 & 1.4 & -0.1 & 0.164 \\
Anterior injury & 8.3 & 1.1 & 0.4 & $<0.001$ \\
TIMI 0 & 5.4 & 1.2 & 0.2 & $<0.001$ \\
LVM/BSA & 0.1 & 0.0 & 0.1 & 0.112 \\
\hline
\end{tabular}

LVM/BSA left ventricular mass/body surface area

\section{Abbreviations}

CMR: Cardiavascular magnetic resonance; IHD: Ischemic heart disease; IS: Infarct size; MaR: Myocardium at risk; MSI: Myocardial salvage index; PCl: Percutaneous coronary intervention; STEMI: ST-elevation myocardial infarction

\section{Acknowledgements}

We would like to acknowledge Helene Jacobsson at the department of Medical Statistics and Epidemiology, Forum Söder, Skane University Healthcare for advising on the statistical analysis and presentation in this manuscript.

\section{Authors' contributions}

HA conceptualized the study. DA, DE, UE, MC, HE, EH, HA participated in the design of the original CHILL-MI, MITOCARE, and/or SOCCER trials. HE, JLB, $\mathrm{HSH}, \mathrm{DA}, \mathrm{DE}, \mathrm{UE}, \mathrm{MC}, \mathrm{HA}$ participated in patient inclusion. HA and DN participated in study design. HE, MC, HA, DN performed MR data analysis. DN drafted the manuscript which was then critically revised by all authors. All authors have read and approved the final manuscript.

\section{Funding}

Funding for the CHILL-MI trial was received from the Region of Skane, Philips Healthcare, Lund University, and Uppsala University. The MITOCARE trial was supported by the European Union under the 7th Framework Programme for RTD -Project MITOCARE- Grant Agreement HEALTH-2010-261034. Funding for the SOCCER trial was received from the Region of Skane. None of the funding bodies played any roles in designing the study, collecting data, performing data analysis, interpreting the data, or writing the manuscript.

\section{Availability of data and materials}

The datasets used and/or analysed during the current study are available from the corresponding author on reasonable request.

\section{Ethics approval and consent to participate}

The MITOCARE trial was approved by the local or regional institutional review boards/ethics committees in each of the 10 respective sites and coordination of the approvals are handled by the safety and ethics monitoring committee [28]. The CHILL-MI trial was approved by the ethics commission of the medical University of Innsbruck and of the University of Vienna for Austria, the committees of science ethics of the capital region for Denmark, and the ethical review board in Lund for Sweden. The SOCCER trial was approved by the regional Ethical Review Board in Lund (Dnr 2011/258)

[29]. All patients provided written informed consent.

\section{Consent for publication}

All patients provided written informed consent.

Table 8 Multivariable analysis, MSI

\begin{tabular}{lllll}
\hline Variable & $\begin{array}{l}\text { Regression } \\
\text { coefficient }\end{array}$ & SE & $\begin{array}{l}\text { Partial } \\
\text { correlation }\end{array}$ & $p$-value \\
\hline Model $r^{2}=0.20$ & & & & \\
Age & -0.2 & 0.1 & -0.1 & 0.070 \\
Female gender & 9.5 & 2.8 & 0.2 & 0.001 \\
Smoker or ex-smoker & 2.5 & 2.3 & 0.1 & 0.271 \\
Anterior injury & -6.5 & 2.3 & -0.2 & 0.005 \\
TIMI 0 & -12.2 & 2.6 & -0.3 & $<0.001$ \\
Pre PCI TnT $<15$ ng/L & 5.2 & 2.3 & 0.1 & 0.027 \\
LVM/BSA & -0.1 & 0.1 & -0.1 & 0.107 \\
\hline
\end{tabular}

LVM/BSA left ventricular mass/body surface area

\section{Competing interests}

Dr. Arheden is a shareholder of Imacor. Drs Arheden, Heiberg, Carlsson, and Engblom consult for Imacor, the core-lab that performed the CMR-analysis for the MITOCARE, CHILL-MI, and SOCCER trials. Dr. Heiberg is the founder and owner of the company Medviso AB, Lund, Sweden. The authors declare that they have no competing interests.

\section{Author details}

${ }^{1}$ Department of Clinical Physiology, Clinical Sciences, Lund University, Lund, Sweden. ${ }^{2}$ Assistance Publique Hôpitaux de Marseille, Hôpital La Timone, Marseille, France. ${ }^{3}$ Department of Cardiology B, Odense University Hospital, Odense, Denmark. ${ }^{4}$ Department of Cardiology B, Oslo University Hospital Ullevål, and Faculty of Medicine, University of Oslo, Oslo, Norway.

${ }^{5}$ Department of Cardiology, Clinical Sciences, Lund University, Lund, Sweden. ${ }^{6}$ Department of Emergency Medicine, Clinical Sciences, Lund University, Lund, Sweden. ${ }^{7}$ Department of Biomedical Engineering, Faculty of Engineering, Lund University, Lund, Sweden. 
Received: 8 January 2019 Accepted: 24 June 2019 Published online: 03 July 2019

\section{References}

1. Reimer KA, Lowe JE, Rasmussen MM, Jennings RB. The wavefront phenomenon of ischemic cell death. 1. Myocardial infarct size vs duration of coronary occlusion in dogs. Circulation. 1977;56:786-94.

2. Lowe JE, Reimer KA, Jennings RB. Experimental infarct size as a function of the amount of myocardium at risk. Am J Pathol. 1978;90:363-79.

3. Lee JT, Ideker RE, Reimer KA. Myocardial infarct size and location in relation to the coronary vascular bed at risk in man. Circulation. 1981;64:526-34.

4. Braunwald E, Kloner RA. Myocardial reperfusion: a double-edged sword? J Clin Invest. 1985;76:1713-9.

5. Wu E, Ortiz JT, Tejedor P, Lee DC, Bucciarelli-Ducci C, Kansal P, Carr JC, Holly TA, Lloyd-Jones D, Klocke FJ, Bonow RO. Infarct size by contrast enhanced cardiac magnetic resonance is a stronger predictor of outcomes than left ventricular ejection fraction or end-systolic volume index: prospective cohort study. Heart. 2008;94:730-6.

6. Roes SD, Kelle S, Kaandorp TAM, Kokocinski T, Poldermans D, Lamb HJ, Boersma E, van der Wall EE, Fleck E, de Roos A, Nagel E, Bax JJ. Comparison of myocardial infarct size assessed with contrast-enhanced magnetic resonance imaging and left ventricular function and volumes to predict mortality in patients with healed myocardial infarction. Am J Cardiol. 2007; 100:930-6.

7. Kelle S, Roes SD, Klein C, Kokocinski T, de Roos A, Fleck E, Bax JJ, Nagel E. Prognostic value of myocardial infarct size and contractile reserve using magnetic resonance imaging. J Am Coll Cardiol. 2009;54:1770-7.

8. Kwong RY, Chan AK, Brown KA, Chan CW, Reynolds HG, Tsang S, Davis RB. Impact of unrecognized myocardial scar detected by cardiac magnetic resonance imaging on event-free survival in patients presenting with signs or symptoms of coronary artery disease. Circulation. 2006;113:2733-43.

9. Writing Group Members, Mozaffarian D, Benjamin EJ, Go AS, Arnett DK, Blaha MJ, Cushman M, Das SR, de Ferranti S, Després J-P, Fullerton HJ, Howard VJ, Huffman MD, Isasi CR, Jiménez MC, Judd SE, Kissela BM, Lichtman JH, Lisabeth LD, Liu S, Mackey RH, Magid DJ, DK MG, Mohler ER, Moy CS, Muntner P, Mussolino ME, Nasir K, Neumar RW, Nichol G, Palaniappan L, Pandey DK, Reeves MJ, Rodriguez CJ, Rosamond W, Sorlie PD, Stein J, Towfighi A, Turan TN, Virani SS, Woo D, Yeh RW, Turner MB. American Heart Association statistics committee, stroke statistics subcommittee. Heart disease and stroke statistics-2016 update: a report from the American Heart Association. Circulation. 2016;133:e38-360.

10. Rosengren A. Sex differences in survival after myocardial infarction in Sweden. Data from the Swedish National Acute Myocardial Infarction register. Eur Heart J. 2001;22:314-22.

11. Gourlay SG, Rundle AC, Barron H. Smoking and mortality following acute myocardial infarction: results from the National Registry of myocardial infarction 2 (NRMI 2). Nicotine Tob Res. 2002;4:101-7.

12. Gottlieb S, Boyko V, Zahger D, Balkin J, Hod H, Pelled B, Stern S, Behar S. Smoking and prognosis after acute myocardial infarction in the thrombolytic era (Israeli thrombolytic national survey). J Am Coll Cardiol. 1996;28:1506-13.

13. Thune JJ, Signorovitch J, Kober L, Velazquez EJ, McMurray JJV, Califf RM, Maggioni AP, Rouleau JL, Howlett J, Zelenkofske S, Pfeffer MA, Solomon SD. Effect of antecedent hypertension and follow-up blood pressure on outcomes after high-risk myocardial infarction. Hypertension. 2008;51:48-54.

14. Motz W, Vogt M, Scheler S, Schwartzkopff B, Strauer BE. Coronary circulation in arterial hypertension. J Cardiovasc Pharmacol. 1991;17(Suppl 2):S35-9.

15. Vatner SF, Shannon R, Hittinger L. Reduced subendocardial coronary reserve. A potential mechanism for impaired diastolic function in the hypertrophied and failing heart. Circulation. 1990;81:III8-14.

16. Melchior $T$, Kober $L$, Madsen $C R$, Seibaek M, Jensen GV, Hildebrandt $P$, TorpPedersen C. Accelerating impact of diabetes mellitus on mortality in the years following an acute myocardial infarction. TRACE study group. Trandolapril cardiac evaluation. Eur Heart J. 1999:20:973-8.

17. Mukamal KJ, Nesto RW, Cohen MC, Muller JE, Maclure M, Sherwood JB, Mittleman MA. Impact of diabetes on long-term survival after acute myocardial infarction: comparability of risk with prior myocardial infarction. Diabetes Care. 2001;24:1422-7.

18. Lamblin N, Fertin M, de Groote P, Bauters C. Cardiac remodeling and heart failure after a first anterior myocardial infarction in patients with diabetes mellitus. J Cardiovasc Med (Hagerstown). 2012;13:353-9.
19. Simonetti OP, Kim RJ, Fieno DS, Hillenbrand HB, Wu E, Bundy JM, Finn JP, Judd RM. An improved MR imaging technique for the visualization of myocardial infarction. Radiology. 2001;218:215-23.

20. Kim RJ, Wu E, Rafael A, Chen E-L, Parker MA, Simonetti O, Klocke FJ, Bonow RO, Judd RM. The use of contrast-enhanced magnetic resonance imaging to identify reversible myocardial dysfunction. N Engl J Med. 2000;343:1445-53.

21. Carlsson M, Ubachs JFA, Hedström E, Heiberg E, Jovinge S, Arheden H. Myocardium at risk after acute infarction in humans on cardiac magnetic resonance. JACC Cardiovasc Imaging. 2009;2:569-76.

22. Aletras AH, Kellman P, Derbyshire JA, Arai AE. ACUT2E TSE-SSFP: a hybrid method for T2-weighted imaging of edema in the heart. Magn Reson Med. 2008;59:229-35.

23. Sörensson P, Heiberg E, Saleh N, Bouvier F, Caidahl K, Tornvall P, Rydén L, Pernow J, Arheden $\mathrm{H}$. Assessment of myocardium at risk with contrast enhanced steady-state free precession cine cardiovascular magnetic resonance compared to single-photon emission computed tomography. J Cardiovasc Magn Reson. 2010;12:25.

24. Friedrich MG, Abdel-Aty H, Taylor A, Schulz-Menger J, Messroghli D, Dietz R. The salvaged area at risk in reperfused acute myocardial infarction as visualized by cardiovascular magnetic resonance. J Am Coll Cardiol. 2008;51: 1581-7.

25. Hedström E, Engblom H, Frogner $F$, Aström-Olsson K, Ohlin H, Jovinge $S$, Arheden $\mathrm{H}$. Infarct evolution in man studied in patients with first-time coronary occlusion in comparison to different species - implications for assessment of myocardial salvage. J Cardiovasc Magn Reson. 2009;11:38.

26. Erlinge D, Götberg M, Lang I, Holzer M, Noc M, Clemmensen P, Jensen U, Metzler B, James S, Bötker HE, Omerovic E, Engblom H, Carlsson M, Arheden H, Östlund O, Wallentin L, Harnek J, Olivecrona GK. Rapid endovascular catheter core cooling combined with cold saline as an adjunct to percutaneous coronary intervention for the treatment of acute myocardial infarction. J Am Coll Cardiol. 2014;63:1857-65.

27. Atar D, Arheden H, Berdeaux A, Bonnet J-L, Carlsson M, Clemmensen P, Cuvier V, Danchin N, Dubois-Rande J-L, Engblom H, Erlinge D, Firat H, Halvorsen S, Hansen HS, Hauke W, Heiberg E, Koul S, Larsen A-I, Le Corvoisier P, Nordrehaug JE, Paganelli F, Pruss RM, Rousseau H, Schaller S, Sonou G, Tuseth V, Veys J, Vicaut E, Jensen SE, Group MITOCARE Study. Rationale and design of the "MITOCARE" study: a phase II, multicenter, randomized, double-blind, placebo-controlled study to assess the safety and efficacy of TRO40303 for the reduction of reperfusion injury in patients undergoing percutaneous coronary in. Cardiology. 2012;123:201-7.

28. Atar D, Arheden H, Berdeaux A, Bonnet J-L, Carlsson M, Clemmensen P, Cuvier V, Danchin N, Dubois-Rande J-L, Engblom H, Erlinge D, Firat H, Halvorsen S, Hansen HS, Hauke W, Heiberg E, Koul S, Larsen A-I, Le Corvoisier P, Nordrehaug JE, Paganelli F, Pruss RM, Rousseau H, Schaller S, Sonou G, Tuseth V, Veys J, Vicaut E, Jensen SE. Effect of intravenous TRO40303 as an adjunct to primary percutaneous coronary intervention for acute ST-elevation myocardial infarction: MITOCARE study results. Eur Heart J. 2015;36:112-9.

29. Khoshnood A, Carlsson M, Akbarzadeh M, Bhiladvala P, Roijer A, Nordlund D, Höglund P, Zughaft D, Todorova L, Mokhtari A, Arheden H, Erlinge D, Ekelund U. Effect of oxygen therapy on myocardial salvage in ST elevation myocardial infarction: the randomized SOCCER trial. Eur J Emerg Med. 2016. https://doi.org/10.1097/MEJ.0000000000000431.

30. Peter Rentrop K, Cohen M, Blanke H, Phillips RA. Changes in collateral channel filling immediately after controlled coronary artery occlusion by an angioplasty balloon in human subjects. J Am Coll Cardiol. 1985;5:587-92.

31. Heiberg E, Sjögren J, Ugander M, Carlsson M, Engblom H, Arheden H. Design and validation of segment--freely available software for cardiovascular image analysis. BMC Med Imaging. 2010;10:1.

32. Nordlund D, Klug G, Heiberg E, Koul S, Larsen TH, Hoffmann P, Metzler B, Erlinge D, Atar D, Aletras AH, Carlsson M, Engblom H, Arheden H. Multivendor, multicentre comparison of contrast-enhanced SSFP and T2-STIR CMR for determining myocardium at risk in ST-elevation myocardial infarction. Eur Heart J Cardiovasc Imaging. 2016;17:744-53.

33. Heiberg E, Ugander M, Engblom H, Götberg M, Olivecrona GK, Erlinge D, Arheden $\mathrm{H}$. Automated quantification of myocardial infarction from MR images by accounting for partial volume effects: animal, phantom, and human study. Radiology. 2008;246:581-8.

34. Du Bois D. Clinical Calorimetry. Arch Intern Med. 1916;XVII:863.

35. De Luca G, Suryapranata H, Dambrink J-H, Ottervanger JP, van 't Hof AWJ, Zijlstra F, Hoorntje JCA, Gosselink ATM, de Boer M-J. Sex-related differences 
in outcome after ST-segment elevation myocardial infarction treated by primary angioplasty: data from the Zwolle myocardial infarction study. Am Heart J. 2004;148:852-6.

36. Mega JL, Morrow DA, Ostör E, Dorobantu M, Qin J, Antman EM, Braunwald E. Outcomes and optimal antithrombotic therapy in women undergoing fibrinolysis for ST-elevation myocardial infarction. Circulation. 2007;115:2822-8

37. Lawesson SS, Alfredsson J, Fredrikson M, Swahn E. A gender perspective on short- and long term mortality in ST-elevation myocardial infarction--a report from the SWEDEHEART register. Int J Cardiol. 2013;168:1041-7.

38. Canali E, Masci P, Bogaert J, Bucciarelli Ducci C, Francone M, McAlindon E, Carbone I, Lombardi M, Desmet W, Janssens S, Agati L. Impact of gender differences on myocardial salvage and post-ischaemic left ventricular remodelling after primary coronary angioplasty: new insights from cardiovascular magnetic resonance. Eur Heart J Cardiovasc Imaging. 2012; 13:948-53.

39. Eitel I, Desch S, de Waha S, Fuernau G, Gutberlet M, Schuler G, Thiele H. Sex differences in myocardial salvage and clinical outcome in patients with acute Reperfused ST-elevation myocardial infarction: advances in cardiovascular imaging. Circ Cardiovasc Imaging. 2012;5:119-26.

40. Langhans B, Ibrahim T, Hausleiter J, Sonne C, Martinoff S, Schömig A, Hadamitzky M. Gender differences in contrast-enhanced magnetic resonance imaging after acute myocardial infarction. Int J Cardiovasc Imaging. 2013;29:643-50.

41. Mehilli J, Ndrepepa G, Kastrati A, Nekolla SG, Markwardt C, Bollwein H, Pache J, Martinoff S, Dirschinger J, Schwaiger M, Schömig A. Gender and myocardial salvage after reperfusion treatment in acute myocardial infarction. J Am Coll Cardiol. 2005;45:828-31.

42. Engblom H, Heiberg E, Erlinge D, Jensen SE, Nordrehaug JE, Dubois-Randé J-L, Halvorsen S, Hoffmann P, Koul S, Carlsson M, Atar D, Arheden H. Sample size in clinical Cardioprotection trials using myocardial salvage index, infarct size, or biochemical markers as endpoint. J Am Heart Assoc. 2016;5:e002708.

43. Kelly TL, Gilpin E, Ahnve S, Henning H, Ross J. Smoking status at the time of acute myocardial infarction and subsequent prognosis. Am Heart J. 1985; 110:535-41.

44. Symons R, Masci PG, Francone M, Claus P, Barison A, Carbone I, Agati L, Galea N, Janssens S, Bogaert J. Impact of active smoking on myocardial infarction severity in reperfused ST-segment elevation myocardial infarction patients: the smoker's paradox revisited. Eur Heart J. 2016;37:2756-64.

45. Chadha SL, Radhakrishnan S, Ramachandran K, Kaul U, Gopinath N. Epidemiological study of coronary heart disease in urban population of Delhi. Indian J Med Res. 1990;92:424-30.

46. Ho KK, Pinsky JL, Kannel WB, Levy D. The epidemiology of heart failure: the Framingham study. J Am Coll Cardiol. 1993;22:6A-13A.

47. Shah AD, Langenberg C, Rapsomaniki E, Denaxas S, Pujades-Rodriguez M, Gale CP, Deanfield J, Smeeth L, Timmis A, Hemingway H. Type 2 diabetes and incidence of cardiovascular diseases: a cohort study in 1.9 million people. Lancet Diabetes Endocrinol. 2015;3:105-13.

48. Scognamiglio R, Avogaro A, Casara D, Crepaldi C, Marin M, Palisi M, Mingardi R, Erle G, Fasoli G. Dalla Volta S. myocardial dysfunction and adrenergic cardiac innervation in patients with insulin-dependent diabetes mellitus. J Am Coll Cardiol. 1998;31:404-12.

49. Abrignani MG, Dominguez L, Biondo G, Di Girolamo A, Novo G, Barbagallo M, Braschi A, Braschi G, Novo S. In-hospital complications of acute myocardial infarction in hypertensive subjects. Am J Hypertens. 2005;18: 165-70.

50. van der Pals J, Hammer-Hansen S, Nielles-Vallespin S, Kellman P, Taylor J, Kozlov S, Hsu L-Y, Chen MY, Arai AE. Temporal and spatial characteristics of the area at risk investigated using computed tomography and $\mathrm{T} 1$ -weighted magnetic resonance imaging. Eur Heart J Cardiovasc Imaging. 2015;16:1232-40

51. Daaboul Y, Korjian S, Weaver WD, Kloner RA, Giugliano RP, Carr J, Neal BJ, Chi G, Cochet M, Goodell L, Michalak N, Rusowicz-Orazem L, Alkathery T, Allaham H, Routray S, Szlosek D, Jain P, Gibson CM. Relation of left ventricular mass and infarct size in Anterior Wall ST-segment elevation acute myocardial infarction (from the EMBRACE STEMI clinical trial). Am J Cardiol. 2016;118:625-31.

\section{Publisher's Note}

Springer Nature remains neutral with regard to jurisdictional claims in published maps and institutional affiliations.

Ready to submit your research? Choose BMC and benefit from:

- fast, convenient online submission

- thorough peer review by experienced researchers in your field

- rapid publication on acceptance

- support for research data, including large and complex data types

- gold Open Access which fosters wider collaboration and increased citations

- maximum visibility for your research: over $100 \mathrm{M}$ website views per year

At BMC, research is always in progress.

Learn more biomedcentral.com/submissions 